\title{
DESENVOLVIMENTO E FITOSSANIDADE DE AMEIXEIRAS TRATADAS COM SILÍCIO EM SISTEMA ORGÂNICO ${ }^{1}$
}

\author{
SILVANA GIROTTO MARTINS FERREIRA², RENATO VASCONCELOS BOTELHO ${ }^{3}$, \\ CACILDA MÁRCIA DUARTE RIOS FARIA ${ }^{3}$, \\ MILENA APARECIDA FERRARI MATEUS ${ }^{4}$, WELTON LUIZ ZALUSKI ${ }^{5}$
}

\begin{abstract}
RESUMO - O objetivo deste trabalho foi avaliar o efeito do silício ( $\mathrm{Si}$ ) aplicado via pulverização foliar em ameixeiras cv. Pluma 7, para o controle da bacteriose (Xanthomonas arborícola pv. pruni), mariposa oriental (Grapholita molesta) e pulgão-verde (Myzus persicae), bem como no desenvolvimento das plantas, em sistema orgânico de produção. Para o ensaio, foi utilizado o produto comercial AgriSil ${ }^{\circledR}\left(98 \%\right.$ de $\left.\mathrm{SiO}_{2}\right)$. O experimento foi conduzido em Guarapuava-PR, durante dois ciclos consecutivos (2010/2011 e 2011/2012). As doses utilizadas foram: $0 ; 1 ; 2 ; 4 \mathrm{e} 8 \mathrm{~g} \mathrm{~L}^{-1}$ do produto comercial, aplicadas quinzenalmente. Nos dois ciclos de avaliação, foram observadas reduções de até $85 \%$ na incidência da bacteriose com efeito quadrático das doses de silício. Os danos causados pela mariposa oriental, o número de pulgões, o diâmetro e o comprimento de ramos das plantas de ameixeira não foram significativamente influenciados pelas aplicações de $\mathrm{SiO}_{2}$. Quanto ao teor de Si foliar, observou-se efeito linear positivo em função das doses de Si.

Termos para indexação: Prunus salicina, nutrição mineral, manejo integrado, agroecologia.
\end{abstract}

\section{DEVELOPMENT AND FITOSSANITY ON PLUM TREES TREATED WITH SILICON IN ORGANIC SYSTEM}

\begin{abstract}
The objective of this study was to evaluate the effect of silicon ( $\mathrm{Si}$ ) applied via foliar in plum trees cv. Pluma 7 for the control of bacterial blight (Xanthomonas arboreal pv. pruni), oriental fruit moth (Grapholita molesta) and green aphid (Myzus persicae), as well as in plant development, in organic management. For this trial it was used the commercial product AgriSil ${ }^{\circledR}\left(98 \% \mathrm{SiO}_{2}\right)$. The experiment was carried out in Guarapuava-PR, Brazil, by two consecutive cycles (2010/2011 and 2011/2012). The doses used were $0,1,2,4$ and $8 \mathrm{~g} \mathrm{~L}^{-1}$ of the commercial product, each two weeks. In both cycles, for the plum bacterial blight, it was verified until $85 \%$ incidence reduction, with quadratic effect of silicon doses. For the damage of oriental fruit moth, number of aphids, diameter and length of shoots no significant difference between the doses of $\mathrm{SiO}_{2}$ were found. For Si leaf content, a positive linear effect was verified in function of Si doses.
\end{abstract} Keywords: Prunus salicina, mineral nutrition, Integrated Management, agroecology.

${ }^{1}$ (Trabalho 078-13). Recebido em: 28-02-2013. Aceito para publicação em: 20-09-2013.

${ }_{2}^{2}$ Mestranda do Programa de Pós-Graduação em Agronomia, Universidade Estadual do Centro-Oeste - UNICENTRO Guarapuava-PR, Brasil. E-mail: silgirotto@zipmail.com.br

${ }^{3}$ Eng. Agr. Dr. Professor Associado. Departamento de Agronomia, Universidade Estadual do Centro-Oeste - UNICENTRO, Rua Simeão Camargo Varella de Sá, 03. CEP 85040-080, Guarapuava-PR. E-mail: rbotelho@unicentro.br

${ }^{4}$ Universidade Federal do Paraná/ UFPR, doutoranda no Programa de Pós-Graduação em Agronomia, Departamento de Fitotecnia e Fitossanitarismo, Curitiba-PR, Brasil. E-mail: miferrarimateus@gmail.com

${ }^{5}$ Estudante de graduação em agronomia pela Universidade Estadual do Centro-Oeste/ UNICENTRO, departamento de Agronomia, Guarapuava-PR, Brasil. E-mail: weltonzaluski_@hotmail.com 


\section{INTRODUÇÃO}

O consumo anual de ameixas no Brasil é de aproximadamente 50.000 toneladas, sendo que $30 \%$ desse total é importado, principalmente do Chile e da Argentina (FACHINELLO et al., 2011). Dentre as fruteiras de clima temperado, a ameixeira é uma das culturas que carecem de desenvolvimento tecnológico, em razão da relativa falta de cultivares com boa adaptação climática e problemas fitossanitários (OLIVEIRA et al., 2011).

Dentre as principais doenças da ameixeira, destaca-se a bacteriose causada por Xanthomonas arboricola pv. pruni, que é responsável por causar sérios danos à parte aérea da planta, como manchas necróticas e queda das folhas. Além disso, o ataque de pragas, como a mariposa oriental Grapholita molesta Busck (Lepidoptera: Tortricidae), que causa danos nos ponteiros e frutos,e do pulgão Myzus persicae Sulzer (Hemiptera: Aphididae), que sugam a seiva e levam à deformação das folhas novas, também comprometem a produção e causam prejuízos ao produtor. O controle dessas pragas e doenças geralmente é realizado de forma convencional, com produtos químicos, que nem sempre são eficientes, além de oferecem riscos, como a contaminação ambiental, a intoxicação humana, além da seleção de patógenos resistentes (OKA, 2010).

Como alternativa ao modelo convencional de agricultura, existe o sistema de produção orgânica que não permite o uso de agrotóxicos, reguladores vegetais e fertilizantes químicos, com o objetivo de obter não somente produtos saudáveis ao consumo humano, mas também a preservação de todo o ecossistema.

Uma das possibilidades para substituir ou diminuir o uso de produtos químicos no controle de pragas e doenças é o uso preventivo do silício (Si), que tem sido reconhecido pelos seus benefícios às plantas cultivadas. Alguns exemplos destes benefícios, são os efeitos positivos que já foram relatados na redução de incidência de doenças bacterianas nas culturas do algodão (OLIVEIRA et al., 2012) e do arroz (XUE et al.; 2010), e de doenças fúngicas nas culturas do arroz (ZANÃO JÚNIOR et al., 2009), do mamoeiro (PRATISSOLI et al., 2007); da melancia (SANTOS et al, 2010) e do feijão (MORAES et al., 2006). Assim como redução significativa nos danos causados por pragas, como relatado em pulgões na cultura do trigo (GOMES et al., 2005; COSTA et al., 2007) e em lagartas na cultura do milho (GOUSSAIN et al. ,2002, NERI et al., 2005).

Este elemento é o segundo em maior abundância na crosta terrestre, perdendo apenas para o oxigênio. Ele se acumula nos tecidos de plantas e pode melhorar o desenvolvimento de várias espécies de vegetais, além de proporcionar maior resistência a pragas e doenças, seja pela promoção de uma barreira mecânica, seja pelo acúmulo de compostos fenólicos, que impedem a infecção por patógenos e diminuem a palatabilidade aos insetos-praga (GOUSSAIN et al., 2002; TERRY e JOICE, 2004).

Com base nestas informações, o objetivo deste trabalho foi avaliar o efeito do uso do silício, aplicado via pulverização foliar em ameixeiras para o controle de insetos-praga, como a mariposa oriental e pulgão-verde, bem como o efeito deste elemento no manejo da bacteriose e no desenvolvimento vegetativo de ameixeiras.

\section{MATERIAL E MÉTODOS}

O experimento foi conduzido em GuarapuavaPR, durante dois ciclos consecutivos (2010/2011 e 2011/2012). As ameixeiras da cv. Pluma 7, com cinco anos de idade, estavam enxertadas sobre porta-enxerto de pessegueiro 'Capdeboscq', com espaçamento 5 × 5 metros e conduzidas em taça. O manejo do pomar experimental, desde o início da implantação, obedeceu ao sistema orgânico de acordo com a legislação brasileira, não tendo sido utilizado nenhum insumo sintético, tais como adubos químicos, inseticidas, fungicidas ou bactericidas (MAPA, 2008).

A adubação com fontes orgânicas foi preferencialmente adotada desde a implantação da área experimental, usando prioritariamente materiais disponíveis na região (esterco bovino, resíduos agrícolas, adubos verdes) em quantidades previamente estimadas de acordo com as necessidades das plantas. Outras fontes não orgânicas permitidas na produção orgânica foram usadas em função da fertilidade do solo e das exigências das plantas (CQFS-RS/SC, 2004), tais como pós-de-rocha, calcário e fosfato natural.

Os tratamentos utilizados foram as doses de 0; $1 ; 2 ; 4$ ou $8 \mathrm{~g} \mathrm{~L}^{-1}$ do produto comercial AgriSil® $\left(98 \%\right.$ de $\left.\mathrm{SiO}_{2}\right)$. As aplicações das soluções aquosas de óxido de silício foram realizadas durante a fase vegetativa, com o auxílio de pulverizador costal (Marca Vonder - 5L), até o ponto de escorrimento (500 mL planta ${ }^{-1}$ ), com periodicidade quinzenal, a partir do início da brotação. Foram feitas no total, 12 pulverizações em cada ciclo, no período de setembro a fevereiro.

$\mathrm{O}$ delineamento experimental foi o em blocos casualizados, com cinco tratamentos, quatro repetições e parcela experimental constituída por 
uma planta. Além dos tratamentos com silício, o controle fitossanitário foi realizado quinzenalmente e de forma intercalada em toda a área experimental, com produtos permitidos na produção orgânica, para o controle de pragas e doenças, como quitosana Superfish ${ }^{\circledR}\left(20 \mathrm{~mL} \mathrm{~L}^{-1}\right)$, óleo vegetal natur'oleo ${ }^{\circledR}$ $\left(20 \mathrm{~mL} \mathrm{~L}^{-1}\right)$, extrato de alho Naturalho ${ }^{\circledR}\left(60 \mathrm{~mL} \mathrm{~L}^{-1}\right)$ e óleo de nem Natuneem ${ }^{\circledR}\left(20 \mathrm{~mL} \mathrm{~L}^{-1}\right)$; de forma preventiva, totalizando 12 pulverizações anuais.

Para avaliar a severidade da bacteriose causada por Xanthomonas arboricola pv. pruni, foram coletadas, quinzenalmente, a partir do aparecimento dos primeiros sintomas, 10 folhas por planta para realização de observações visuais de acordo com a escala diagramática proposta por Citadin et al. (2008). Com os dados da severidade obtidos de 8 avaliações em cada ciclo, foi determinada a área abaixo da curva de progresso da doença (AACPD), segundo Shaner e Finney (1977).

Para determinar o grau de infestação de pragas, 10 ramos anuais por planta, previamente identificados, foram avaliados quinzenalmente quanto a ponteiros dos ramos com danos causados pela mariposa oriental (Grapholita molesta) e realizada a contagem da população de pulgões (Myzus persicae).

Para verificar o efeito do silício no desenvolvimento vegetativo das ameixeiras, foram avaliados o comprimento $(\mathrm{cm})$ e o diâmetro $(\mathrm{mm})$ dos ramos do ano no final do mês de maio, por ocasião da queda das folhas. A análise foliar de $\mathrm{Si}\left(\mathrm{g} \mathrm{kg}^{-1}\right)$ foi realizada a partir de amostras de 10 folhas por planta, retiradas da parte mediana de ramos do ano, em janeiro de 2011, pelo método colorimétrico do azul de molibdênio, em presença de ácido oxálico e de ácido ascórbico (BATAGLIA et al., 1978).

A produção de ameixas não pode ser avaliada em função da ocorrência de geadas primaveris, nos dois ciclos produtivos, no início do mês de setembro, que levaram ao abortamento de flores.

Os resultados foram submetidos à análise de variância e, quando significativos, foi realizada a análise de regressão, ao nível de $5 \%$ de probabilidade, utilizando-se do programa estatístico SISVAR 5.0 (FERREIRA, 2011).

\section{RESULTADOS E DISCUSSÃO}

Nos dois ciclos de avaliação, houve redução da AACPD causada por Xanthomonas arborícola pv. pruni, com efeito quadrático, pela análise de regressão (Figuras 1A e 1B). Embora nos dois ciclos de avaliação a AACPD tenha diminuído conforme o aumento das doses de Si, no primeiro ciclo (Figura 1A), a AACPD foi consideravelmente menor do que no segundo ciclo (Figura 1B). Isso possivelmente ocorreu devido a um efeito acumulativo da doença de um ciclo para o outro. Segundo Feliciano e Daines (1970), durante o inverno, a bactéria sobrevive nos espaços intercelulares do córtex, floema e parênquima do xilema, somando-se ao novo ataque no segundo ciclo, ocasionando assim uma AACPD maior.

No primeiro ano de avaliação da incidência da bacteriose, nas plantas em que se aplicou o Si na concentração de $1 \mathrm{~g} \mathrm{~L}^{-1}$, a AACPD foi $48 \%$ menor do que na testemunha, enquanto para os tratamentos 2; 4 e $8 \mathrm{~g} \mathrm{~L}^{-1}$ de $\mathrm{Si}$, a redução foi de $71,5 \%, 72,1 \%$ e $79,5 \%$, respectivamente (Figura 1A). No segundo ano do experimento, os resultados foram muito semelhantes aos do primeiro, observando-se que, com a aplicação do tratamento $1 \mathrm{~g} \mathrm{~L}^{-1}$, houve redução de $47,9 \%$ da AACPD em relação à testemunha, e nos tratamentos 2; 4 e $8 \mathrm{~g} \mathrm{~L}^{-1}$, a redução foi de $70 \%, 75,8$ o e $85,7 \%$, respectivamente (Figura $1 \mathrm{~B}$ ).

A redução da AACPD da bacteriose para os diferentes tratamentos utilizados neste experimento, possivelmente, ocorreu pelo aumento da resistência das plantas proporcionada pelo uso do Si. Segundo Terry e Joice (2004), este elemento confere maior proteção a estresses bióticos, como o ataque de insetos-praga, e abióticos, como vento e granizo. A deposição de Si na parede celular pode ser considerada como uma barreira física que dificulta o ataque de insetos e a infecção por bactérias, além de induzir alguns mecanismos de resistência nas plantas, como a síntese de compostos fenólicos.

Resultados semelhantes foram obtidos por Oliveira et al. (2012), em pesquisa com mancha angular do algodão (Xanthomonas citri subsp. malvacearum), os quais verificaram que a aplicação ao solo da dose de 1,50 $\mathrm{g} \mathrm{SiO}_{2} \mathrm{~kg}^{-1}$ proporcionou redução de $55 \%$ na severidade dessa doença. Xue et al. (2010) verificaram que plantas de arroz inoculadas com Xanthomonas oryzae pv. oryzae e tratadas com silício também tiveram a severidade dessa doença reduzida em níveis de até $75 \%$.

Para o diâmetro e o comprimento médio dos ramos, observou-se que não houve efeito significativo das aplicações foliares de Si no desenvolvimento vegetativo das plantas de ameixeira, em nenhum dos ciclos avaliados (Tabela 1). Por outro lado, Bhavya et al. (2010), em experimento em condições de campo, na Índia, com videiras cv. Azul Bangalore, testando as dose de 2;4 e $6 \mathrm{ml} \mathrm{L}^{-1}$ de $\mathrm{SiO}_{2}$, observaram maior comprimento de ramos, maior área foliar e maior teor

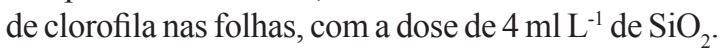
Resende et al. (2007) verificaram maior massa fresca total e circunferência de plantas de alface quando 
tratadas com diferentes doses de silício $(0,0 ; 0,9$; 1,$8 ; 2,7$ e 3,6 $\mathrm{L} \mathrm{ha}^{-1}$ ), em única aplicação via foliar, após o transplantio para canteiros.

Da mesma forma como observado quanto ao desenvolvimento vegetativo das plantas de ameixeira, os danos causados pela mariposa oriental e as populações de pulgão-verde não foram influenciados pelas aplicações de $\mathrm{SiO}_{2}$ embora os valores absolutos sempre tenham sido inferiores à testemunha (Tabelas 2 e 3). No entanto, Carvalho et al. (1999), em experimento com a cultura do sorgo, verificaram que, nas parcelas tratadas com $4 \mathrm{~mL}$ planta $^{-1}$ de silicato de sódio $\left(27 \%\right.$ de $\left.\mathrm{SiO}_{2}\right)$, houve diminuição significativa do número de pulgões nas folhas tratadas com silício em relação à testemunha. Segundo vários autores (GOMES et al., 2005; NERI et al., 2005; COSTA et al., 2007), essa resistência deve-se à formação de barreiras mecânicas ou a mudanças bioquímicas nas plantas, aumentando a síntese de toxinas que podem agir como repelentes.

Houve efeito linear positivo para os teores foliares de silício, em função das doses aplicadas
(Figura 2). Zanão Júnior et al. (2009), trabalhando com aplicação de Si para aumentar a resistência do arroz à mancha-parda, causada pelo fungo Bipolaris oryzae, observaram teores foliares de Si de até 4,3 vezes maiores que a testemunha com aplicação via foliar.

Diante dos resultados encontrados, verificase que a aplicação de óxido de silício a partir de $1 \mathrm{~g} \mathrm{~L}^{-1}$ pode ser utilizada para auxiliar no controle da bacteriose da ameixeira. Essa doença é de difícil controle, sendo que, em cultivo convencional, são necessárias várias aplicações de produtos químicos. A aplicação de Si pode incrementar a defesa natural das plantas quando submetidas a algum tipo de estresse, seja ele biótico, seja abiótico e, com isso, tornando-se mais resistentes ao ataque de pragas e doenças, podendo reduzir as aplicações de agroquímicos. Apesar de os resultados para mariposa oriental e pulgão não terem sido significativos, houve diminuição desses insetos nos dois períodos de avaliações com a dose $1 \mathrm{~g} \mathrm{~L}^{-1}$ de Si.

TABELA 1- Comprimento e diâmetro de ramos de ameixeiras cv. Pluma 7, no primeiro (2010-2011) e no segundo (2011-2012) ciclos (Guarapuava-PR, 2011).

\begin{tabular}{ccccc}
\hline \multicolumn{3}{c}{ Safra 2010/2011 } & \multicolumn{2}{c}{ Safra 2011/2012 } \\
\hline Doses Si (g L-1) & $\begin{array}{c}\text { Comprimento ramos } \\
(\mathrm{cm})\end{array}$ & $\begin{array}{c}\text { Diâmetro } \\
\text { ramos }(\mathrm{mm})\end{array}$ & $\begin{array}{c}\text { Comprimento } \\
\text { ramos }(\mathrm{cm})\end{array}$ & $\begin{array}{c}\text { Diâmetro ramos } \\
(\mathrm{mm})\end{array}$ \\
\hline 0 & 62,5 & 20,0 & 87,6 & 21,0 \\
1 & 45,0 & 18,9 & 74,6 & 20,2 \\
2 & 70,6 & 19,4 & 89,3 & 21,3 \\
4 & 56,9 & 19,4 & 92,4 & 20,1 \\
8 & 61,2 & 20,2 & 106,9 & 21,2 \\
$\mathrm{CV}(\%)$ & 19,8 & 5,79 & 27,0 & 4,8 \\
$\operatorname{Pr}>\mathrm{Fc}$ & 0,082 & 0,63 & 0,49 & 0,92 \\
\hline
\end{tabular}

TABELA 2- Porcentagem de ponteiros danificados pela Mariposa oriental e número médio de pulgões por ramo, em ameixeiras cv. Pluma 7, no $1^{\circ}$ ciclo de avaliações (Guarapuava-PR, 2010-2011).

\begin{tabular}{ccccccccccc}
\hline \multicolumn{4}{c}{$\begin{array}{c}\text { Mariposa oriental } \\
(\% \text { ponteiros atacados })^{1}\end{array}$} & \multicolumn{5}{c}{$\begin{array}{c}\text { Pulgão-verde } \\
\left(\mathrm{n}^{\circ} \text { indivíduos }\right)^{2}\end{array}$} \\
\hline $\begin{array}{c}\mathrm{Si} \\
\left(\mathrm{g} \mathrm{L}^{-1}\right)\end{array}$ & $15 / 12$ & $30 / 12$ & $13 / 01$ & $27 / 01$ & Média & $15 / 12$ & $30 / 12$ & $13 / 01$ & $27 / 01$ & Média \\
\hline 0 & 1,8 & 8,5 & 10,0 & 12,1 & 8,1 & 24,2 & 16,5 & 0 & 0 & 10,2 \\
1 & 3,2 & 2,9 & 5,7 & 6,5 & 4,6 & 10,2 & 11,0 & 0 & 0 & 5,3 \\
2 & 2,0 & 7,0 & 7,3 & 10,5 & 6,7 & 22,9 & 16,1 & 0 & 0 & 9,7 \\
4 & 2,1 & 7,2 & 7,6 & 7,0 & 6,0 & 22,7 & 17,7 & 0 & 0 & 10,0 \\
8 & 1,3 & 8,7 & 7,5 & 9,6 & 6,8 & 26,5 & 20,9 & 1,2 & 0 & 12,1 \\
\hline $\mathrm{CV}(\%)$ & 60,4 & 40,4 & 44,6 & 22,3 & & 37,3 & 29,4 & 27,6 & 0 & \\
$\mathrm{Pr}>\mathrm{Fc}$ & 0,97 & 0,57 & 0,91 & 0,33 & & 0,56 & 0,68 & 0,35 & 0 & \\
\hline
\end{tabular}

${ }^{1}$ Porcentagem de ponteiros com danos de mariposa oriental, em 10 ramos marcados por planta. ${ }^{2}$ Total de indivíduos em 10 ramos, previamente identificado, por planta. 

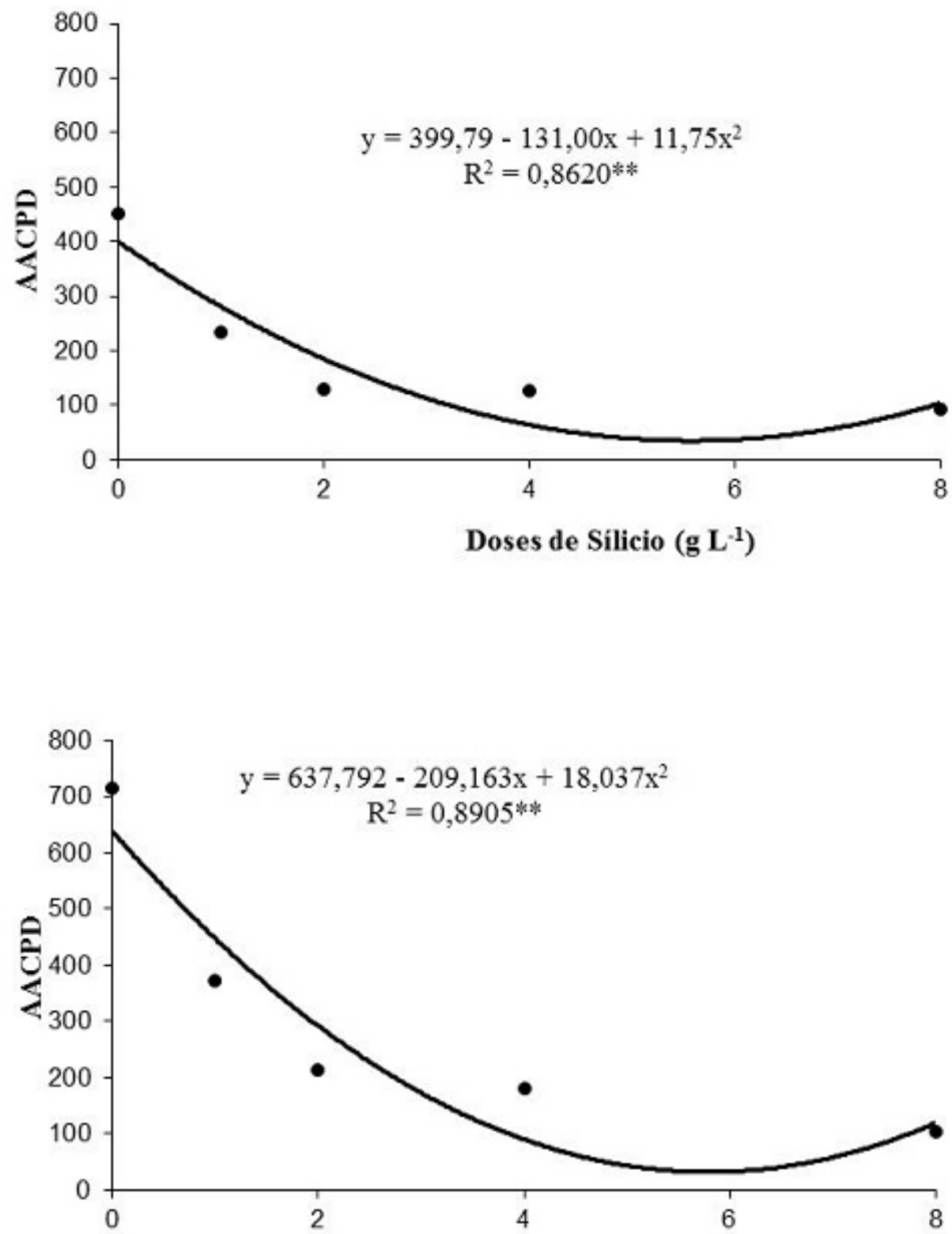

\section{Doses de Silício $\left(\mathrm{g} \mathrm{L}^{-1}\right)$}

FIGURA 1- Área abaixo da curva de progresso da doença de bacteriose causada por Xanthomonas arborícola pv. pruni em ameixeiras cv. Pluma 7, tratadas com diferentes doses de silício, no primeiro ciclo (A) e segundo ciclo (B) (Guarapuava-PR, 2012). 
TABELA 3- Porcentagem de ponteiros com danos de mariposa oriental e número de pulgões por ramo, em ameixeiras cv. Pluma 7, no $2^{\circ}$ ciclo de avaliações (Guarapuava-PR, 2011-2012).

\begin{tabular}{|c|c|c|c|c|c|c|c|c|c|c|}
\hline \multicolumn{5}{|c|}{$\begin{array}{c}\text { Mariposa oriental } \\
(\% \text { ponteiros atacados })^{1}\end{array}$} & \multicolumn{6}{|c|}{$\begin{array}{l}\text { Pulgão-verde } \\
\left(\mathrm{n}^{\circ} \text { indivíduos }\right)^{2}\end{array}$} \\
\hline $\mathrm{Si}\left(\mathrm{g} \mathrm{L}^{-1}\right)$ & $23 / 11$ & $08 / 12$ & $21 / 12$ & $04 / 01$ & Média & $23 / 11$ & $08 / 12$ & $21 / 12$ & $04 / 01$ & Média \\
\hline 0 & 1,8 & 5,3 & 11,0 & 12,7 & 7,7 & 8,7 & 8,3 & 6,7 & 0 & 5,9 \\
\hline 1 & 0,5 & 1,7 & 2,4 & 3,6 & 2,0 & 1,3 & 5,1 & 1,0 & 0 & 1,8 \\
\hline 2 & 0,5 & 4,6 & 4,0 & 5,3 & 3,6 & 9,9 & 9,7 & 7,2 & 1,3 & 7,0 \\
\hline 4 & 0,3 & 1,9 & 6,9 & 4,7 & 3,4 & 0,9 & 3,4 & 5,7 & 0,4 & 3,4 \\
\hline 8 & 3,9 & 4,2 & 9,6 & 5,9 & 5,9 & 10,9 & 6,7 & 8,5 & 0 & 6,5 \\
\hline CV (\%) & 41,3 & 35,3 & 52,9 & 45,9 & & 44,0 & 59,3 & 52,2 & 32,4 & \\
\hline $\mathrm{Pr}>\mathrm{Fc}$ & 0,15 & 0,38 & 0,42 & 0,22 & & 0,09 & 0,78 & 0,55 & 0,51 & \\
\hline
\end{tabular}

${ }^{1}$ Porcentagem de ponteiros com danos de mariposa oriental de 10 ramos marcados por planta

${ }^{2}$ Total de indivíduos em 10 ramos previamente identificados, por planta.

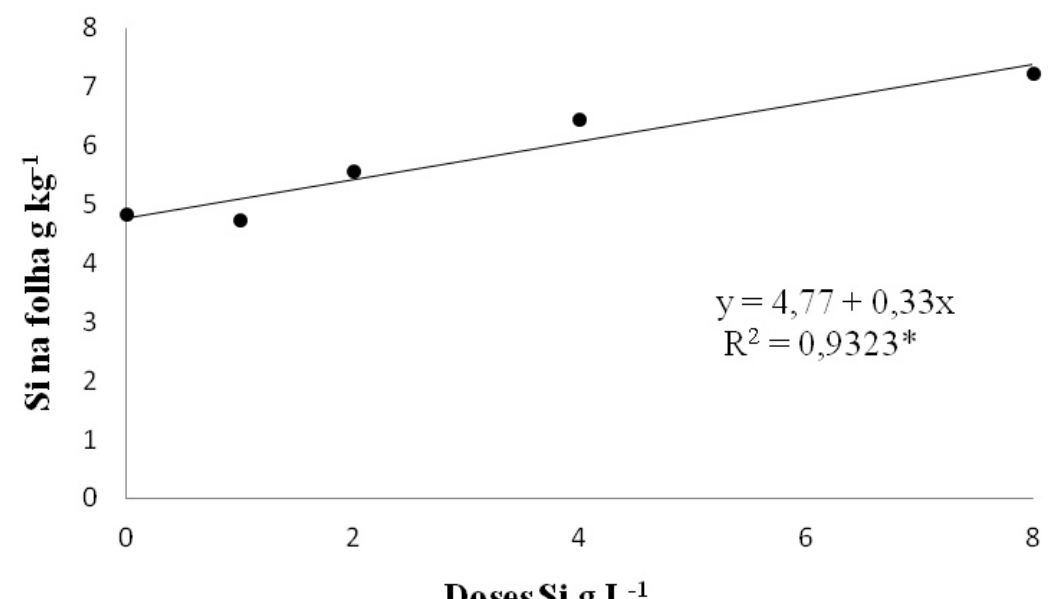

Doses Si $g \mathbf{L}^{-1}$

FIGURA 2- Silício em folhas de ameixeira cultivar Pluma 7 (Guarapuava-PR, 2012).

\section{CONCLUSÃO}

Em ameixeiras cv. Pluma 7, o uso de óxido de silício em doses entre 2 e $8 \mathrm{~g} \mathrm{~L}^{-1}$, aplicado via foliar, reduz significativamente a incidência da bacteriose causada por Xanthomonas arboricola pv. pruni, podendo ser uma alternativa promissora para o controle desta doença, sobretudo para o sistema de produção orgânica, sem haver, contudo, efeitos no desenvolvimento vegetativo das plantas e no controle da mariposa oriental e do pulgão-verde.

\section{AGRADECIMENTOS}

À Coordenadoria de Aperfeiçoamento de Pessoal de Nível Superior-CAPES, pela concessão da bolsa de Mestrado ao primeiro autor.

\section{REFERÊNCIAS}

BATAGLIA, O. C.; TEIXEIRA, J. P. F.; FURLANI, A. M. C.; FURLANI, P. R.; GALLO, J. R. Métodos de análise química de plantas. Campinas: IAC, 1978. 31p. (Circular, 87).

BHAVYA, H.K.; NACHEGOWDA, V.; JANAGATH, S.; SREENIVAS, K. N.; PRAKASH, N. B. Effect of foliar silicic acid and boron acid in 'Bangalore Blue' grapes. In: INTERNATIONAL CONFERENCE ON SILICON IN AGRICULTURE, 5., 2011. Proceedings... p.7.

CITADIN, I.; ASSMANN, A. P.; MAZARO, S. M.; GOUVÊA, A.; DANNER, M. A.; MALAGI, G. Escala diagramática para avaliação da severidade de bacteriose em pessegueiro. Revista Brasileira de Fruticultura, Jaboticabal, v.30, n.2, p.327-330, 2008. 
COSTA, R. R.; MORAES, J. C.; ANTUNES, C. S. Resistência induzida em trigo ao pulgão Schizaphis graminum (hemiptera: aphididae) por silício e acibenzolar-s-methyl. Ciência e Agrotecnologia, Lavras, v.31, n., p.393-397, 2007.

CQFS - Comissão de Química e Fertilidade do SoloRS/SC. Manual de adubação e de calagem para os Estados do Rio grande do Sul e de Santa Catarina. 10. ed. Porto Alegre: SBCS-Núcleo Regional Sul, 2004. 400p.

FACHINELLO, J.C.; PASA, M.S.; SCHMTIZ, J.D.; BETEMPS, D. L. Situação e perspectivas da fruticultura de clima temperado no Brasil. Revista Brasileira de Fruticultura, Jaboticabal, p. 109-120, 2011. Volume especial.

FELICIANO, A.; DAINES, R. H. Factors influencing ingress of Xanthomonas pruni through peach leaf scars and subsequent development of spring cankers. Phytopathology, Saint Paul, v.60, p.1720-1726, 1970.

FERREIRA, D. F. Sisvar: a computer statistical analysis system. Ciência e Agrotecnologia, Lavras, v. 35, n.6, p. 1039-1042, 2011.

GOMES, F. B.; MORAES, J.C.; SANTOS, C.D.; GOUSSAIN, M.M. Resistance induction in wheat plants by silicon and aphids. Scientia Agricola, Piracicaba, v. 62, n. 6, p.547-551, 2005.

GOUSSAIN, M. M.; MORAES, J. C.; CARVALHO, J. G.; NOGUEIRA, N. L.; ROSSI, M. L. Efeito da aplicação de silício em plantas de milho no desenvolvimento biológico da lagarta-do-cartucho Spodoptera frugiperda (J. E. Smith) (Lepidoptera: Noctuidae). Neotropical Entomology, Londrina, v.31, n.2, p. 305-310, 2002.

MAPA - Ministério da Agricultura, Pecuária e Abastecimento. Instrução Normativa ${ }^{\circ}$ 64, de 18 de dezembro de 2008.

MORAES, S. R.; ALVES, E.; POZZA, E. A.; CARVALHO, J. G.; LIMA, P. H.; BOTELHO, A. $O$. Efeito de fontes de silício na incidência e na severidade da antracnose do feijoeiro. Fitopatologia Brasileira, Lavras, v.31, n.1, p.69-75, 2006.

NERI, D. K. P.; MORAES, J. C.; GAVINO, M. A. Interação silício com inseticida regulador de crescimento no manejo da lagarta-do-cartucho Spodoptera frugiperda (J. E. Smith) (Lepidoptera: Noctuidae) em milho. Ciência e Agrotecnologia, Lavras, v.29, n.4, p.1167-1174, 2005.
OKA, Y. Mechanisms of nematode suppresion by organic soil amendments - A review. Applied Soil Ecology, Amsterdam, v44, p.101-115, 2010.

OLIVEIRA, J. C.; ALBUQUERQUE, R. L. R.; GONDIM, D. M. F.; OLIVEIRA, J. T. A.; SOUZA, E. B. Reduction of the severity of angular leaf spot of cotton mediated by silicon. Journal of Plant Pathology, Bari, v.1, n. 2, p.297-304, 2012.

OLIVEIRA, M. C.; PIO, R.; RAMOS, J.D.; ALVARENGA, A.A.; SANTOS, V.A.; FANTE, C. Seleção de ameixeiras promissoras para a Serra da Mantiqueira. Revista Ceres, Viçosa, MG, v.1, 58, n.4, p.531-535, 2011.

PRATISSOLI, D.; ALMEIDA, G. D.; JESUS JÚNIOR, W. C.; VICENTINI, V. B.; HOLTZ, A. M.; COCHETO, J. G. Fertilizante organomineral e argila silicatada como indutores de resistência à varíola do mamoeiro. Idesia, Arica, v. 25, n. 2, p. 63-67, 2007.

RESENDE, G.M.; YURI, J.E.; SOUZA, R.J. Épocas de plantio e doses de silício no rendimento de alface tipo americana. Horticultura Brasileira, Brasília, v.25, n.3, p.455-459, 2007.

SANTOS, G. R.; CASTRO NETO, M. D.; CARVALHO, A. R. S.; FIDELIS, R. R.; AFFÉRI, F. S. Fontes e doses de silício na severidade do crestamento gomoso e produtividade da melancia. Bioscience Journal, Uberlândia, v.26, n.2, p. 266272, 2010 .

SHANER, G.; FINNEY, R. E. The effect of nitrogen fertilization on the expression. Of slow-mildewing resistance in Knox wheat. Phytopathology, Saint Paul, v.67, n.8, p.1.051-1.056, 1977.

TERRY, L. A.; JOYCE, D.C. Elicitors induced disease resistance in postharvest horticultural crops: a brief review. Postharvest Biology Technology, Amsterdam, v.32, p.1-13, 2004.

XUE, G. F.; SUN, W. C.; SONG, A. L.; LI, Z. J.; FAN, F. L.; LIANG, Y. C. Influences of silicon on rice growth, resistance to bacterial blight and activity of pathogenesis-related proteins. Scientia Agriculture Sinica, Beijing, v.43, n.4, p.690- 697, 2010.

ZANÃO JÚNIOR, L. A.; FONTES, R. L. F.; ÀVILA, V. T. Aplicação do silício para aumentar a resistência do arroz à mancha-parda. Pesquisa Agropecuária Brasileira, Brasília, v.44, n.2, p.203-206, 2009. 